\title{
Wound care using metronidazole in a patient with diabetic foot ulcer: a case report
}

\author{
Agus Santosa $^{1}$, Okta Fajar Silviana ${ }^{2}$, Neneng Khasanah ${ }^{3}$ \\ ${ }^{1,2}$ Departement of Medical Surgical Nursing, Universitas Muhammadiyah Purwokerto, Indonesia \\ ${ }^{3}$ Departement of Medical Ward, Banyumas Regional Public Hospital, Indonesia
}

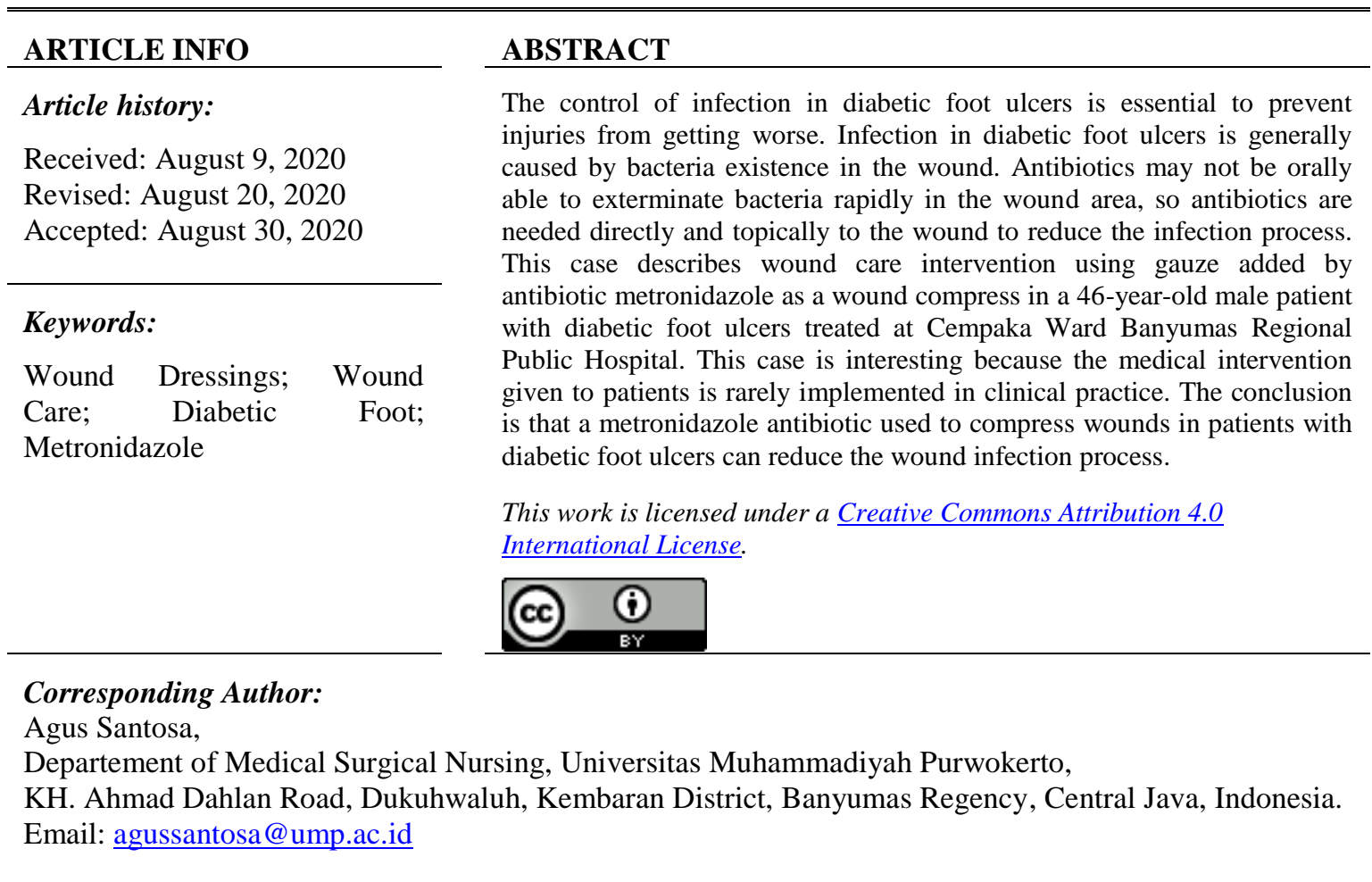

\section{INTRODUCTION}

Diabetic Foot Ulcer (DFU) is a severe complication of diabetes because it results in high morbidity and mortality. According to research, the prevalence of DFU in the world ranges from 6.3\% (95\% CI: 5.4$7.3 \%$ ) [1]. The probability of amputation in DFU sufferers is $34.1 \%$, and the estimated death rate of the patient is around $5.5 \%$ in the first year and $42 \%$ in the next five years [2]. The growth of DFU usually occurs through 3 stages. The initial stage is the formation of a callus that results from neuropathy. Motoric neuropathy causes physical deformity in the legs, and sensory neuropathy causes sensory loss, causing trauma. Finally, trauma to the callus causes subcutaneous bleeding and eventually erodes and becomes an ulcer [3].

Standard management of wound care in patients with DFU including wound debridement [4], proper dressings [5], reducing exudate [6], wound offloading or stopping the wound so that it does not expand [7], adequate vascularization [8], and controlling infection and blood sugar [9,10]. Multidisciplinary collaboration is indispensable in treating patients with DFU to get proper medical treatment [11]. Adjuvant therapies from various studies have also proved useful in improving wound healing [10,12]. In this manuscript, we are reporting a case of DFU patients given adjuvant therapy in wound care with compress metronidazole.

\section{RESEARCH METHOD}

This research is a case study. The study's subject was a 46-year-old male patient with DFU. A research location in Banyumas General Hospital, Central Java, Indonesia. The patient was subjected to a wound care intervention using routine metronidazole once a day for five days. The variables studied were wound condition (cleanliness, color, exudate, necrosis, odor), blood leukocyte levels, and the number of bacterial colonies. 


\section{RESULTS AND DISCUSSIONS}

\subsection{Case presentation}

A 46-year-old man with DFU was treated at Cempaka ward of Banyumas Regional Public Hospital. The patient had suffered from Diabetes Mellitus (DM) for five years and also had a hereditary disease of DM from his father. The wound on the foot had been around six months, and the patient had never treated the wound to any medical service; the patient only cleaned the wound himself using warm water and Betadine. The depth of the wound was $4 \mathrm{~cm}$, the width was $4 \mathrm{~cm}$, the length was $10 \mathrm{~cm}$, the color was yellowish greenish and brownish, there were a lot of exudates and dead tissue/necrosis in almost all wounds, and malodor at a strong level (Figure 1). Random Blood Glucose: $450 \mathrm{mg} / \mathrm{dL}$, Leukocytes: 16.26 x $10^{\wedge}$ 3/uL (increased), BW: $102 \mathrm{~kg}$, BH: $167 \mathrm{~cm}$, BMI $36.57 \mathrm{~kg} / \mathrm{m} 2$ (Class II Obesity), Blood Pressure: 120/80 mmHg, Temperature: 370C, Respiration Rate: $21 \mathrm{x} / \mathrm{m}$, and Pulse: $90 \mathrm{x} / \mathrm{m}$. The cultural examination results of bacteria by clinical pathologists on patients' wounds including Staphylococcus sp., Pseudomonas sp., Proteus sp., Shigella sp., Klebsiella sp., A.faecalis sp. and E.coli sp, with the number of bacterial colonies of 2.9 x $107 \mathrm{CFU} / \mathrm{ml}$.

Doctors on metatarsal 4 and 5 performed amputations because he had experienced necrotic. According to the standard operating procedures for wound care, nurses performed routine wound care once a day for five consecutive days. The wounds were compressed using gauze that had been added with antibiotic metronidazole. Ceftriaxone antibiotics were also prescribed intravenously by the doctor. The results of observation of wounds on the fifth day, the patient's wound became cleaner with reddish wound color, exudate and necrosis reduced, leukocyte values became normal 4,2 10^3/uL and malodor at a mild level. The bacterial colony's examination result decreased to $1.5 \times 103 \mathrm{CFU} / \mathrm{ml}$ (Figure 2).

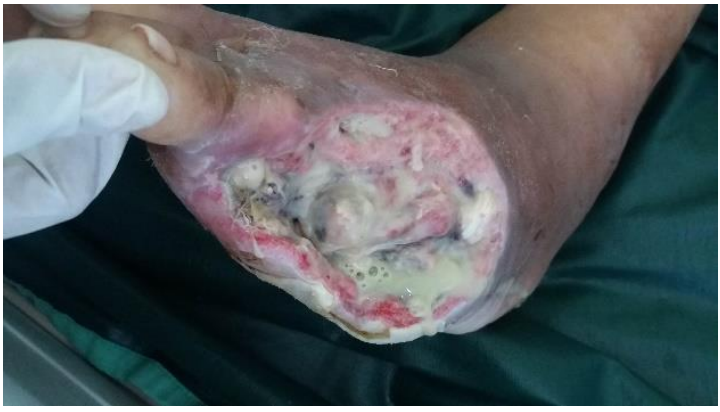

Figure 1. Before wound care

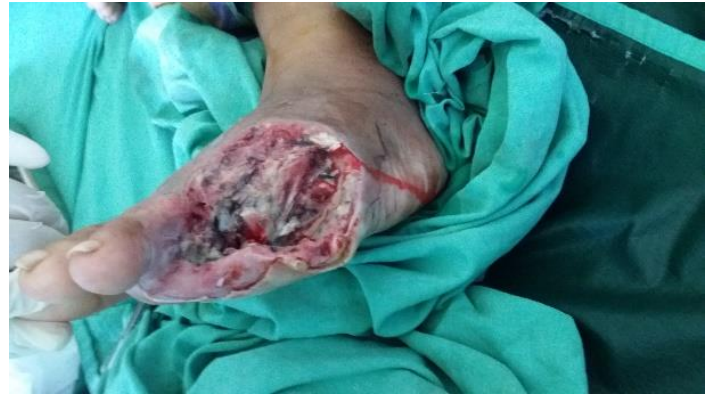

Figure 1. Five days after wound care

\subsection{Discussions}

The subject of this case study is male, with the age of 46 years. More DFU sufferers are in males compared to females [13]. Increased prevalence of DFU in males is associated with decreased joint mobility and higher leg pressure in males [14]. Other studies have shown that male diabetes patients have more risk (twice) of experiencing neuropathy, which is the primary factor causing DFU compared to women, so the incidence of DFU in males is higher [15].

Most DFU sufferers in the age range of 45-64 years [13]. There is a decrease in water content, skin elasticity, and skin integrity in that age range. Besides, atrophy of apocrine glands and sebaceous will cause the skin to become dry and more prone to injury [16]. Decreased angiogenesis and impaired wound healing also play a role in the occurrence of DFU, in addition to peripheral sensory neuropathy, which is a significant factor causing DFU $[17,18]$.

The microbiological examination is done by the culture of the patient's pus material. A culture examination was performed to determine pathogenic infections or bacteria that cause DFU [19]. The type of bacteria that mostly infects DM patients with DFU is Staphylococcus aureus. This bacterium is a commensal organism on the skin's surface, but in a wound condition on the skin, this bacterium will be pathogenic. The pathogenicity of $\mathrm{S}$. aureus is because these bacteria produce toxins and enzymes that can cause tissue damage [20].

Necrotic tissue in DFU will be a medium for bacterial growth, which is a decomposition of the medium due to bacterial activation. This decomposition process depends on the content of the medium used as food for bacteria. Living tissue contains much protein whose molecular composition contains sulfur bonds; the release of sulfur into free ions will bind to other elements such as hydrogen, causing odor and other secretions [21].

Empirical antibiotic administration must include active agents against Staphylococcus aureus [22], [23]. Empirical antibiotics can be given singly or in combination [24]. In this case, the patient is given antibiotics in a combination way but with a different administration way. Ceftriaxone type antibiotics are 
given intravenously, while metronidazole type antibiotics are given topically by directly compressing the patient's wound.

The ceftriaxone performance mechanism is the same as other $\beta$-lactam antibiotics, which inhibit microorganism cell wall synthesis by interfering with the transpeptidase reaction [25]. Ceftriaxone is a broadspectrum antibiotic that is effective against most aerobic bacteria, both positive gram or weight/negative gram or weight and has activity against some bacteria. Gram-negative anaerobes are commonly found in ulcers/gangrene [26,27]. Based on the Infectious Diseases Society of America recommendations, ceftriaxone is a drug of choice for empirical therapy in moderate to severe ulcer/gangrene infections with infecting bacteria MSSA, Streptococcus spp, Enterobacteriaceae, and anaerobes [28].

Metronidazole is suitable for the severity of ulcers according to the Wagner scale 1-3 [29]. Metronidazole is a nitroimidazole derivative with a molecular formula C6H9N3O3 and a molecular weight of 171.15396 [30]. Metronidazole is a nitroimidazole compound with a broad spectrum of anti-protozoa and anti-bacterial properties, has an action to fight the combination of gram-positive and gram-negative bacteria [31]. Its mechanism of action is that it inhibits nucleic acid synthesis by damaging DNA. As anti protozoa, metronidazole works by destroying the protozoa, whereas as a radiation-sensitizer, metronidazole can effectively damage unwanted cells [32].

\section{CONCLUSION}

The combination of wound care and the administration of compress metronidazole as well as antibiotic ceftriaxone intravenously, which is bactericidal, has an impact on reducing bacterial activity, decreasing the number of colonies, decreasing the process of decomposition of the medium, which will ultimately reduce the odor and secretion of the wound which results in wound repair in patients. However, this study's results need to be carried out in clinical trials to know the level of effectiveness better statistically.

\section{Acknowledgments}

The researchers present our deepest gratitude to the nursing staff and medical team at Banyumas Regional Public Hospital to conduct this research smoothly.

\section{REFERENCES}

[1] P. Zhang, J. Lu, Y. Jing, S. Tang, D. Zhu, and Y. Bi, "Global epidemiology of diabetic foot ulceration: a systematic review and meta-analysis," Ann. Med., vol. 49, no. 2, pp. 106-116, Feb. 2017.

[2] S. H. Won et al., "Risk factors associated with amputation-free survival in patient with diabetic foot ulcers," Yonsei Med. J., vol. 55, no. 5, pp. 1373-1378, Sep. 2014.

[3] A. Victor et al., "Measurement and Interpretation of the Ankle-Brachial Index," Circulation, vol. 126, no. 24, pp. 2890-2909, Dec. 2012.

[4] Edwards J and S. Stapley, "Debridement of diabetic foot ulcers," Cochrane Database Syst. Rev., no. $1,2010$.

[5] W. J. Frances Game, "Dressing and Diabetic Foot Ulcers: A Current Review of the Evidence," Plast. Reconstr. Surg., vol. 138, no. 3S, pp. 158S-164S, 2016.

[6] A. F. Mavrogenis et al., "Current concepts for the evaluation and management of diabetic foot ulcers," EFORT open Rev., vol. 3, no. 9, pp. 513-525, Sep. 2018.

[7] A. L. M. de Oliveira and Z. Moore, "Treatment of the diabetic foot by offloading: a systematic review," J. Wound Care, vol. 24, no. 12, pp. 560-570, Dec. 2015.

[8] Z. Zhang, L. Lv, and S. Guan, "Wound bed preparation for ischemic diabetic foot ulcer," Int. J. Clin. Exp. Med., vol. 8, no. 1, pp. 897-903, Jan. 2015.

[9] J. Xiang, S. Wang, Y. He, L. Xu, S. Zhang, and Z. Tang, "Reasonable Glycemic Control Would Help Wound Healing During the Treatment of Diabetic Foot Ulcers," Diabetes Ther., vol. 10, no. 1, pp. 95-105, Feb. 2019.

[10] E. Everett and N. Mathioudakis, "Update on management of diabetic foot ulcers," Ann. N. Y. Acad. Sci., vol. 1411, no. 1, pp. 153-165, Jan. 2018.

[11] L. M. A. Dutra et al., "Prognosis of the outcome of severe diabetic foot ulcers with multidisciplinary care," J. Multidiscip. Healthc., vol. 12, pp. 349-359, May 2019.

[12] B. E. Sumpio, "Contemporary evaluation and management of the diabetic foot," Scientifica (Cairo),, vol. 2012, p. 435487, 2012.

[13] L. Yazdanpanah et al., "Incidence and Risk Factors of Diabetic Foot Ulcer: A Population-Based Diabetic Foot Cohort (ADFC Study)-Two-Year Follow-Up Study,” Int. J. Endocrinol., vol. 2018, p. 7631659, Mar. 2018. 
[14] K. Al-Rubeaan et al., "Diabetic foot complications and their risk factors from a large retrospective cohort study," PLoS One, vol. 10, no. 5, pp. e0124446-e0124446, May 2015.

[15] S. Khalique, "Evaluation of the effect of inadaptable risk factors \&amp; social status on Diabetic Foot," Int. J. Endorsing Heal. Sci. Res., vol. 2, no. 2 SE-Articles, Dec. 2014.

[16] S. Gist, I. Tio-Matos, S. Falzgraf, S. Cameron, and M. Beebe, "Wound care in the geriatric client," Clin. Interv. Aging, vol. 4, pp. 269-287, 2009.

[17] H. Brem et al., "Healing of elderly patients with diabetic foot ulcers, venous stasis ulcers, and pressure ulcers," Surg. Technol. Int., vol. 11, pp. 161-167, Feb. 2003.

[18] K. Bowering and J. M. Embil, "Foot Care," Can. J. Diabetes, vol. 37, pp. S145-S149, Apr. 2013.

[19] P. G. Bowler, B. I. Duerden, and D. G. Armstrong, "Wound microbiology and associated approaches to wound management," Clin. Microbiol. Rev., vol. 14, no. 2, pp. 244-269, Apr. 2001.

[20] C. Dunyach-Remy, C. Ngba Essebe, A. Sotto, and J.-P. Lavigne, "Staphylococcus aureus Toxins and Diabetic Foot Ulcers: Role in Pathogenesis and Interest in Diagnosis," Toxins (Basel)., vol. 8, no. 7, p. 209, Jul. 2016.

[21] J.-L. Richard, A. Sotto, and J.-P. Lavigne, "New insights in diabetic foot infection," World J. Diabetes, vol. 2, no. 2, pp. 24-32, Feb. 2011.

[22] A. Dezfulian et al., "Bacteriological study of diabetic foot infections in an Iranian hospital," Iran. Red Crescent Med. J., vol. 13, no. 8, pp. 590-591, Aug. 2011.

[23] K. T. Kwon and D. G. Armstrong, "Microbiology and Antimicrobial Therapy for Diabetic Foot Infections," Infect. Chemother., vol. 50, no. 1, pp. 11-20, Mar. 2018.

[24] H. Tchero, P. Kangambega, L. Noubou, B. Becsangele, S. Fluieraru, and L. Teot, "Antibiotic therapy of diabetic foot infections: A systematic review of randomized controlled trials," Wound Repair Regen., vol. 26, no. 5, pp. 381-391, Sep. 2018.

[25] D.M. Richards, R.C. Heel, R.N. Brogden, T.M. Speight, G.S. Avery, "Ceftriaxone A Review of its Antibacterial Activity, Pharmacological Properties and Therapeutic Use," Drugs, vol. 27, no. 6, pp. 469-527, 1984.

[26] G. Ravizzola, C. Bonfanti, E. Savoldi, and A. Turano, "Ceftriaxone against gram-negative and grampositive bacteria: bactericidal and post-antibiotic effect.," Chemioterapia, vol. 4, no. 3, pp. 204-208, Jun. 1985

[27] H. Gómez-Arámbula, A. Hidalgo-Hurtado, R. Rodríguez-Flores, A.-M. González-Amaro, A. Garrocho-Rangel, and A. Pozos-Guillén, "Moxifloxacin versus Clindamycin/Ceftriaxone in the management of odontogenic maxillofacial infectious processes: A preliminary, intrahospital, controlled clinical trial," Journal of clinical and experimental dentistry, vol. 7, no. 5. DDS, Resident, Department of Orofacial Surgery; Hospital "Ignacio Morones Prieto", San Luis Potosi, SLP, Mexico., pp. e634-9, 2015.

[28] B. A. Lipsky et al., "2012 Infectious Diseases Society of America Clinical Practice Guideline for the Diagnosis and Treatment of Diabetic Foot Infectionsa," Clin. Infect. Dis., vol. 54, no. 12, pp. e132e173, Jun. 2012.

[29] J. C. Dumville, B. A. Lipsky, C. Hoey, M. Cruciani, M. Fiscon, and J. Xia, "Topical antimicrobial agents for treating foot ulcers in people with diabetes," Cochrane database Syst. Rev., vol. 6, no. 6, pp. CD011038-CD011038, Jun. 2017.

[30] National Center for Biotechnology Information., "Metronidazole, CID=4173," 2019. .

[31] S. M. FINEGOLD, "Metronidazole,” Ann. Intern. Med., vol. 93, no. 4, pp. 585-587, Oct. 1980.

[32] S. A. Dingsdag and N. Hunter, "Metronidazole: an update on metabolism, structure-cytotoxicity and resistance mechanisms," J. Antimicrob. Chemother., vol. 73, no. 2, pp. 265-279, Oct. 2017. 